\title{
Efficacy of a Trauma Intervention for Women in a Security Housing Unit
}

\author{
Nena Messina ${ }^{1 *}$, Elizabeth Zwart ${ }^{2}$ and Stacy Calhoun ${ }^{3}$ \\ ${ }^{1}$ UCLA Integrated Substance Abuse Programs and Envisioning Justice Solutions Inc., USA \\ ${ }^{2}$ Harvard Kennedy School MPP Candidate and Harvard Business School MBA Candidate, USA \\ ${ }^{3}$ UCLA Integrated Substance Abuse Programs and Envisioning Justice Solutions, Inc., USA
}

${ }^{\star}$ Corresponding author: Nena Messina, UCLA Integrated Substance Abuse Programs, 11075 Santa Monica Blvd., Suite 200, Los Angeles, CA 90025, USA; Tel: 310-801-8996; E-mail: nmessina@mednet.ucla.edu

Received: July 01, 2020; Accepted: July 19, 2020; Published: July 31, 2020

\begin{abstract}
The high rates of trauma exposure, post-traumatic stress disorder (PTSD), and related substance use disorders among incarcerated women suggests a significant need for trauma-informed treatment for women in correctional settings. Despite this need, there is a dearth of studied and effective interventions. This pilot study assessed the effectiveness of a brief trauma-informed intervention on a population of incarcerated women in the Security Housing Unit (SHU) of the California Institution for Women. Confinement in a SHU is considered the second highest level of security in a prison, second only to housing for condemned women. Healing Trauma [1] is a 6-session brief intervention that was designed for women who have experienced trauma associated with adverse childhood experiences. The intervention was delivered twice a week with two-hour long sessions in closed groups of 4-6 women. The sample consisted of $39 \mathrm{SHU}$ participants who volunteered for the program and pilot study. Data were collected prior to the start of the first session and upon completion of the last session on these primary outcomes: depression, anxiety, PTSD, aggression, anger, resilience, empathy, and social connectedness. The results demonstrated strong support for the efficacy of this brief intervention for women housed in SHUs. Participants exhibited significant improvement across depression, anxiety, PTSD, aggression (all 5 sub-measures), anger (1 of 2 sub-measures) and social connectedness $(\mathrm{P}=0.05)$ from the brief intervention. Effect sizes were moderate to large in size, with the largest impact on physical aggression (Cohen's $\mathrm{d}$ ranged from 0.389 to 0.819 ). The results provide preliminary evidence that a brief trauma-informed program can be successfully implemented and impactful with women incarcerated in a high level of secure custody. This builds upon previous work showing similar positive outcomes among men in SHUs and women in the general prison population.
\end{abstract}

\section{Background}

More than 6,500 women currently reside in California's state prisons, with two-thirds serving lengthy or life sentences for violent crimes [2]. As the empirical and theoretical knowledge base on violent crime is heavily influenced by data on men, more studies focused on the needs of incarcerated women are needed. Accurate knowledge about women's pathways into violent behavior is of fundamental importance to the design of appropriate gender-responsive and trauma-informed program service delivery for successful rehabilitation.

\section{Adverse Childhood Experiences among Justice- Involved Women}

Research among incarcerated women over the past two decades consistently shows extensive histories of trauma and abuse during childhood (e.g., physical abuse, sexual abuse, and household dysfunction). A recent study in California shows that among 768 incarcerated women, Adverse Childhood Experiences (ACEs) prior to the age of 16 were reported as follows: $64 \%$ of the women reported emotional abuse; $58 \%$ reported physical abuse; $57 \%$ reported sexual abuse; $70 \%$ had divorced parents; $40 \%$ witnessed domestic violence;
$65 \%$ had alcohol/drug use in their home; $38 \%$ had mental illness in their home; and 39\% had an incarcerated parent [3]. Another study directly compared the histories of adverse childhood experiences among 425 incarcerated men and 314 incarcerated women [4] and showed that women were significantly more likely to report emotional abuse and neglect ( $40 \%$ versus $20 \%, \chi^{2}=34.8, p<0.001$ ), physical abuse $\left(29 \%\right.$ versus $\left.20 \%, \chi^{2}=7.58, p<0.006\right)$, and sexual abuse $(39 \%$ versus $\left.9 \%, \chi^{2}=100.80, p<0.001\right)$.

Histories of trauma and abuse are consistently reported in the literature as critical factors negatively impacting the lives of women [57] showed that the impact of ACEs on health outcomes of 500 women on parole was strong and cumulative (finding that greater exposure to ACEs increased the likelihood of 12 of 18 health and mental healthrelated outcomes). In a large statewide study in California, Messina and colleagues found that $46 \%$ of incarcerated women $(\mathrm{N}=4,386)$ reported witnessing continued violence in their home and being a victim of childhood physical abuse was significantly associated with being returned to prison [8]. ACEs reported among women offenders have been retrospectively linked to an increased likelihood of adolescent conduct disorder, teen pregnancy, chronic addiction, early 
criminal activity, prostitution, homelessness, and Intimate Partner Violence (IPV) in adolescent and adult relationships $[7,9,10]$.

Violence and victimization during the life course are not isolated incidents in women's lives. Often victimization becomes a pattern for women, repeated from relationship to relationship. Women also continue to be victims of violence while in custody, potentially suffering sexual and physical abuse from interpersonal relationships they have formed in prison, from conflict with other residents, and from custody officers $[11,12]$. Thus, the intimate partner violence experienced in their adult lives continues in their custodial life.

\section{Childhood Trauma and Female-Perpetrated Violence}

Childhood trauma is also highly correlated with femaleperpetrated violence [13-15] analyzed survey data from a random sample of incarcerated women $(N=574)$ and found significant indirect paths from childhood adversity, through victimization, to perpetration of violence against romantic partners $(\beta=0.20)$ and others $(\beta=0.19)$. A recent study of 1,113 incarcerated women in California revealed the effect of multiple factors in women's early life that contribute to their perpetration of violence [16]. Regression analyses indicate that the experience of physical abuse and arrest under the age of 18 significantly increased women's risk of engaging in intimidation $\left(r^{2}=0.15 ; \mathrm{n}=430, p<0.05\right)$, minor physical abuse $\left(r^{2}=\right.$ $0.19 ; \mathrm{n}=775, p<0.05)$, and even severe physical abuse $\left(r^{2}=0.18 ; \mathrm{n}=\right.$ $443, p<0.05)$ against others. These results demonstrate that women's early (i.e., before age 18) exposure to trauma and/or the criminal justice system shared strong correlations with adult violence towards others. Although women comprise a small proportion of violent offenders in total [17] women offenders are consistently reported to have more complex histories of exposure to violence, trauma, and abuse than their male counterparts $[4,18]$

\section{Security Housing Units Implementing Segregation and Isolation}

Violent and aggressive behavior in prison often results in disciplinary actions that can lead to isolation and segregation. A Security Housing Unit (SHU) can be used as a disciplinary tool for serious crimes that take place during incarceration. Thus, segregation becomes a secondary sentence imposed by the correctional facility that is unrelated to the conviction for which the person is incarcerated, often referred to as prison "jail" [12,19] The literature also indicates that for women segregation is used for more minor infractions such as disrespect, drug use, mental health crises (e.g., suicide attempts), and refusal to participate in programs (Still Worse than Second-Class, 2019). The United States Department of Justice defines segregation as the "removal from the general inmate population; placement in a locked room or cell (alone or with another); and an inability to leave ... for the vast majority of the day 22 hours a day." (Report and Recommendation Concerning the Use of Restrictive Housing, 2016, p. 8.).

Research on segregation during imprisonment has concluded that these circumstances can be correlated with adverse psychological affects) [20-26] specifically noted that many of the negative affective conditions experienced by residents in the SHU are analogous to those of trauma victims, such as poor impulse control, random outbursts of violence, anxiety, depression, insomnia, and suicide ideation. The American Psychological Association suggests that segregation and isolation exacerbate existing psychological vulnerabilities and can trigger trauma symptoms such as flashbacks, chronic hypervigilance, and a pervasive sense of hopelessness [27].

Other research on the use of segregation has focused on selfharming behavior. One study demonstrated that acts of self-harm, including those that were serious and potentially fatal, were significantly more likely to be engaged in by those who suffered from serious mental illness and by those in solitary confinement [28]. Moreover, women are more likely to engage in self-harming behaviors compared with men [29]. Many researchers contend that in-custody programs focused on trauma are needed to deter self-harming behaviors and to provide the necessary tools to avoid conflict with staff and other women, which often results in a SHU sentence. However, residents in the SHU receive virtually no opportunity for program services and are completely isolated from the general population and visitation.

\section{Relational-Cultural Theory of Development}

Relational-Cultural theory describes women's psychological development in the context of relationships and their connection to others [30]. Relational theory recognizes the different ways in which women and men develop psychologically and emphasizes the centrality of relationships in women's lives [31]. Relational theory views women's psychological development as growth with an emphasis on connection, not separation. Studies [32,33] have shown that women in prison struggle to maintain their prior relationships, and often seek to create a new relational context in their lives (e.g., creating prison families; and closeness and mutuality with other women).

Women who suffer from life-long trauma with a SHU sentence and a complete lack of social contact are likely to fall victim to the adverse effects associated with isolation [21,23-26,34]. Moreover, women with mental health challenges often require protective custody in higher numbers, commit rule violations more frequently, and are more likely to receive solitary confinement as a punishment $[35,36]$. The consequence is a disproportionately high percentage of women in the SHU with mental health problems, exacerbating the need for appropriate mental health services.

\section{Trauma-Informed and Gender-Responsive Treatment Outcomes}

Historically, services for incarcerated women have been based on the needs of men, despite women having very diverse and complex problems in comparison [37,38]. With an increased understanding of the lifelong impact of trauma, clinicians recognize specific issues for women and their relation to criminal involvement and have been able to establish treatment guidelines for trauma and PTSD. Traumarelated difficulties are best treated in stages with the present-focused first stage focusing on safety, education, and skill building (Substance Abuse and Mental Health Services, 2014) [39].

When interventions target the unique needs of incarcerated women (i.e., being gender-responsive, trauma-informed, and 
relational) outcomes are improved. Messina, Calhoun, and Braithwaite [40] found significant reductions in PTSD symptomology among 62 incarcerated women who participated in a Peer Facilitated 20-session trauma-informed intervention grounded in Relational-Cultural Theory (i.e., Beyond Violence) [41]. In a randomized controlled trial [42] compared the 20 session Beyond Violence intervention with a 44-session treatment as usual group (i.e., Assaultive Offender Program), both delivered by trained clinicians. All women improved with regard to their PTSD symptoms and depression; however, there were significant between group differences whereby women in Beyond Violence had stronger declines in anxiety $(F=5.32, p<0.05)$ and on anger measures (using the STAXI State Anger Scale) $(F=8.84, p<0.05)$ than the comparison group.

A recent comprehensive meta-analysis conducted [42] examined whether psychological treatments with men and women incarcerated for violent offenses are effective in preventing community recidivism and institutional misconduct. A total of 27 controlled studies containing 7,062 violent offenders were included in the meta-analysis. The authors state that overall, treatment program services significantly reduced violent and general/nonviolent recidivism. They concluded that the impact of multimodal treatment is most promising, as it was associated with the strongest treatment effects. Because women offenders report greater exposure to childhood trauma and abuse and have more extensive histories of mental health problems and substance use disorders, when compared to their male counter parts [43] multimodal interventions that address the critical factors associated with IPV and aggressive behavior are suggested for reductions in and prevention of violence.

\section{Landmark Changes in California Corrections}

In response to California's prison overcrowding, Assembly Bill 109: Public Safety Realignment Act, 2011, created a shift in prison populations, more so in women's prisons, whereby the overall prison population is now comprised of more serious and violent offenders (California Public Safety Realignment Act, Legislative Bill $A B$ 109) [44]. Those now sentenced to and remaining in prison are offenders who predominantly have a conviction for a serious crime (e.g., violence, use of weapon, rape, kidnapping, etc.) and are serving lengthy to life sentences.

Moreover, in 2013 and 2014 the California Institution for Women (CIW) came under great scrutiny with an organized hunger strike in the SHU to protest California's use of solitary confinement, followed by an unprecedented increase in suicides, particularly among women in the SHU. This prompted a report by the California Office of the Inspector General on the policies, procedures, and conditions within CDCR's SHUs (Inspector General Special Report, 2013) [45]. The report indicated that women serving sentences in a SHU are not privy to any of the programs or services that are made available to the larger prison population and further recommended that CDCR reduce lengthy SHU sentences and to reduce their female SHU population by one third.

As a result, CDCR Female Offender Program Services has made great strides toward providing SHU program services to reduce the re- occurrence of violence and increase safety. Most recently, the CDCR has begun to better understand the critical role of ACEs surrounding anger, aggression, and conflict. The department understands that it is imperative to develop and provide trauma-informed programs to address violent and aggressive behaviors while creating a safe environment for both staff and participant. In 2019, the CDCR was ordered by California's Governor Newsom to provide manualized, gender-responsive, and trauma-informed substance use service programs consistently across all 35 California prisons. ${ }^{1}$ This pilot study sought to assess the overall effectiveness of a brief trauma-informed intervention, based in Relational-Cultural Theory (i.e., Healing Trauma: A Brief Intervention for Women) [1] to reduce trauma-related difficulties and aggressive behaviors as measured by depression, anxiety, PTSD symptoms, aggression, and anger among women housed in the SHU at CIW. This area of research can ultimately result in the delivery of evidence-based interventions, which may create a greater understanding of the resulting trauma from histories of violence and abuse for women and reduce the reoccurrence of such trauma.

\section{Methods}

Human Subjects approvals were obtained from the state of California Committee for Protection of Human Subjects, the California Department of Corrections and Rehabilitation's Research Oversite Committee, and the University of California, Los Angeles Institutional Review Board prior to any contact with participants. The study began in July of 2017 and data collection ended in June 2019.

\section{Hypothesis}

Based on the results of studies that tested the impact of longer $(20+$ session $)$ gender-responsive and trauma-informed interventions for women [39,45-48] it was hypothesized that a shorter, genderresponsive and trauma-informed intervention would exhibit statistically significant improvement on the measures tested for women in SHUs, whose sentences may not allow for longer programming.

\section{Program Description}

Healing Trauma $(H T)$ is a brief, trauma-informed intervention designed for women who have experienced trauma and violence associated with ACEs. HT is based in Relational-Cultural Theory and is designed for delivery in settings in which a short-term intervention is needed. It comprises six, 2-hour sessions in closed groups of up to $4-8$ women. The materials are gender responsive and reflect an understanding of the impact of trauma on women. The intervention focuses on three core elements: (1) an understanding of what trauma is, (2) its process, and (3) its impact on both the inner self (thoughts, feelings, beliefs, values) and the outer self (behavior and relationships). The program content specifically addresses childhood trauma, family/relationship dysfunction, and victimization. It also challenges antisocial norms to reduce the violence and aggression that has been normalized in many women's lives. The HT curriculum includes a variety of therapeutic approaches: Cognitive Behavioral Therapy (CBT), expressive arts, mindfulness, and guided imagery.

\footnotetext{
${ }^{1}$ Helping Men Recover and Helping Women Recover became the core content in the substance use programs in all 35 prisons in the State of California [46].
} 
HT consists of the following 2-hour sessions: Session 1: Welcome and Introduction to the Subject of Trauma; Session 2: Power and Abuse; Session 3: The Process of Trauma and Self-Care; Session 4: The ACE Questionnaire and Anger; Session 5: Healthy Relationships; Session 6: Love, Endings, and Certificates. There is a Facilitator Guide and Participant Workbook for each program. Antisocial patterns are addressed by building self-management skills through CBT sessions on the connection between thinking, feeling, and behavior (anger and violence). Risk factors for dysfunctional relationships are addressed and both abusive and supportive relationship characteristics are explored throughout the content.

\section{Staff Facilitators \& Session Logistics}

All staff responsible for managing and/or facilitating the HT program in the SHU attended a 2-day in-depth training on the $H T$ curriculum that was facilitated by the program's author, Stephanie Covington, Ph.D. The HT program was facilitated by two trained Program Coordinators (the facilitator was not a CDCR staff member). The women were released from their cell confinement, given the participant workbooks, and were able to participate in the group with the use of secured desks within the SHU. Women were required by the institution to be shackled to the desks at all times while they were free from their cell.

\section{Eligible Participants}

All women housed in the SHU at CIW who had enough time remaining in the SHU term to fully complete the 6-week curriculum were eligible to participate in the $H T$ program and corresponding study. All women housed in the SHU were asked by the trained facilitator if they wanted to participate in the $H T$ program and evaluation. Women who wished to participate in the program and the evaluation, and who had enough time left on their sentence to complete the program, met with a research staff member for the consent process and were administered a pre-program questionnaire. They were then scheduled to participate in the next available set of $H T$ sessions. Within one to two weeks of completing the intervention, each participant was administered a post-program survey by research staff. Changes over the course of the intervention on measures of interest were then computed.

A total of 45 women housed in the SHU participated in the HT program over the course of one year and 39 of those women completed the post-program survey (with an $87 \%$ follow-up rate). Reasons for attrition included premature release from the SHU to the general population (2), missing too many sessions or dropping out of the program (2), scheduling conflicts in obtaining the survey (2). The analysis is conducted on the 39 women who completed at least 5 of the 6 sessions as well as the pre- and post-program surveys.

\section{Data Analysis}

Analysis strategies included descriptive and inferential statistics based on background characteristics of participants. Descriptive statistics included percentages, means, and measures of variance. Frequency tables were used to examine cell sizes for categorical variables and non-normality for continuous variables. Where categorical variables had small cell sizes, categories were collapsed to create cells of sufficient size. Paired-sample $t$-tests were conducted to assess changes in the main outcomes across time, allowing for the examination of change over time per individual as well as the findings for the group as a whole. Thus, we do not need to control for other variables (e.g., age or race, etc.) because each person is their own control case and demographic variables will not vary over time.

\section{Measures}

To assess the effectiveness of the $H T$ program, data were collected during the pre- and post-assessments on fourteen measures. Standardized instruments included detailed questions about demographics, childhood and adult trauma, mental health, substance use, and criminal justice involvement. The feasibility of these measures and procedures were previously found to be effective and valid [45].

\section{Depression (Patient Health Questionnaire - Depression Subscale)}

The Patient Health Questionnaire Depression Subscale is a 9-item subscale that measures current depressive symptomology. Participants report on the symptoms they have experienced in the preceding two-week period. Responses are based on a 4-point Likert-type scale ranging from 0 (Not at all) to 3 (Nearly every day) and are summed into an overall symptom severity scale score that falls between 0 and 27 .

\section{Anxiety (Patient Health Questionnaire - Anxiety Subscale)}

The Patient Health Questionnaire Anxiety Subscale is a 6-item subscale that measures anxiety symptoms felt over the past four weeks. Responses are based on a 4-point Likert-type scale ranging from 0 (Not at all) to 3 (Nearly every day) and are summed into an overall symptom severity scale score that falls between 0 and 18 .

\section{PTSD (Short Screening Scale for DSM-IV PTSD (Modified Version))}

The modified version of the Short Screening Scale for DSM-IV Posttraumatic Stress Disorder is used to assess current symptoms of PTSD. Respondents who responded affirmatively to the question "In your life, have you ever had any experience that you considered frightening, horrible, or upsetting?" were then asked to complete a 7-item Short Screening Scale, concerning symptom frequency in the prior four-week period. Item responses were based on a Likert-type scale, ranging from 0 (Not at all) to 3 (Nearly every day), and scale scores ranged from 0 to 21 .

\section{Aggression (Buss-Warren Aggression Questionnaire (AQ))}

Buss-Warren Aggression Questionnaire (AQ), formally the Buss Perry Aggression Questionnaire, is a 34-item instrument used to assess anger and aggression (Buss \& Warren, 2000). The respondent rates the description on a Likert-type scale, ranging from 1 (Not at all like me) to 5 (Completely like me). The Buss-Warren includes five sub-scales: Physical Aggression (8 questions 8-40 range), Verbal Aggression (5 questions, 5 - 25 range), Anger (7 questions, 7 - 35 range), Hostility (8 questions, 8 - 40 range), and Indirect Aggression (6 questions, 6 - 30 range). 


\section{Anger (Rev Instrumental and Expressive Representation Scales)}

The Revised Instrumental and Expressive Representation Scales have 16 items with 2 sub-scales (instrumental and expressive) assessing anger expression. Instrumental anger is a more outward expression of anger that is often used to control others. In contrast, expressive anger is characterized by holding in or suppressing anger until there is an "explosion" of emotion. In the first subscales, respondents answered the degree of agreement about 8 items measuring instrumental anger, including "I believe that physical force is needed to get through to some people" and "If I hit someone and hurt them, they were asking for it." The second subscales assessed expressive anger using 8 items such as "During a physical fight I feel out of control" and "After a physical fight I feel drained and guilty." Participants responded on a scale from 1 (Strongly Disagree) to 5 (Strongly Agree). Some items were reverse scored so that higher scores indicate stronger anger expression. The eight items from each subscale are summed with a range of 8-40 for each sub-scale.

\section{Resilience (The Brief Resilient Coping Scale)}

The BRCS is a brief 4-item, unidimensional measure designed to capture to what extent an individual copes with stress in a resilient fashion. Participants responded on a scale from 1 (Does not describe me at all) to 5 (Describes me very well) and total summed scores range from 4 to 20. Higher scores indicate increased resilience.

\section{Empathy (Interpersonal Reactivity Index)}

The Interpersonal Reactivity Index is a measure of dispositional empathy. The instrument contains four 7-item subscales, each tapping a separate facet of empathy, of which two were scored. The Perspective Taking (PT) scale measures the reported tendency to spontaneously adopt the psychological point of view of others in everyday life (e.g., "I sometimes try to understand my friends better by imagining how things look from their perspective"). The Empathic Concern (EC) scale assesses the tendency to experience feelings of sympathy and compassion for unfortunate others (e.g., "I often have tender, concerned feelings for people less fortunate than me"). Participants responded on a scale from 1 (Does not describe me at all) to 4 (Describes me very well) with some items reverse scored. Scores were summed with a range of 7-28 for each sub-scale.

\section{Social Connectedness (Social Connectedness Scale-Revised)}

The Social Connectedness Scale-Revised assesses experiences of closeness in interpersonal contexts, as well as difficulties establishing and maintaining a sense of closeness as evidenced by a mean item score equal to or greater than 3.5 (Lee \& Lee, 2001; Lee \& Robbins, 1995). The scale consists of 20 items that are scored on a scale of 1 (Strongly Disagree) to 6 (Strongly Agree) and some items were reverse scored. The score is represented as a mean item score with range 1-6.

\section{Demographics}

Prior to receiving the HT programming, each woman self-reported characteristics such as their ethnicity, marital status, age, education level, arrest history, drug and alcohol use history, and childhood and adulthood experiences with trauma (Tables 1-4). Of the 39 women who participated in the HT program, just under $80 \%$ are people of color, most have never been married, and over half did not graduate from high school. Most also have a significant history of involvement with the justice system. Among the women surveyed, the average age

Table 1: Basic demographics $(\mathrm{n}=39)$.

\begin{tabular}{|c|c|c|c|}
\hline Description & $\%$ & Mean & SD \\
\hline Race/Ethnicity & & & \\
\hline Latina/Hispanic & $38.5 \%$ & & \\
\hline White & $20.5 \%$ & & \\
\hline Black & $20.5 \%$ & & \\
\hline Multi-racial and other & $20.5 \%$ & & \\
\hline Marital Status & & & \\
\hline Never married & $60.5 \%$ & & \\
\hline Married or living together & $26.3 \%$ & & \\
\hline Divorced/separated/widowed & $13.2 \%$ & & \\
\hline Current Age & & 34.4 & \\
\hline Education prior to incarceration & & & \\
\hline No high school degree & $51.3 \%$ & & \\
\hline High school degree/GED & $17.9 \%$ & & \\
\hline Some higher education & $30.8 \%$ & & \\
\hline
\end{tabular}

Table 2: Criminal justice histories $(\mathrm{n}=39)$.

\begin{tabular}{|c|c|c|c|}
\hline Description & $\%$ & Mean & SD \\
\hline Age of first arrest & & 16.3 & $(4.95)$ \\
\hline Lifetime arrests & & 16.6 & $(23.02)$ \\
\hline Total years incarcerated & & 12.6 & $(9.09)$ \\
\hline Number of times previously incarcerated in SHU ( $\mathrm{n}=26)$ & & 4.8 & $(3.85)$ \\
\hline Lifetime years previously incarcerated in SHU ( $\mathrm{n}=26)$ & & 2.7 & $(2.12)$ \\
\hline Charged with new crime during incarceration & $64.1 \%$ & & \\
\hline
\end{tabular}

Table 3: Substance use histories $(n=39)$.

\begin{tabular}{|c|c|}
\hline Description & $\%$ \\
\hline Used alcohol or drugs during the 12 months prior to current incarceration? & $89.7 \%$ \\
\hline Frequency of alcohol use prior to arrest & \\
\hline $2-3$ times per week/nearly every day & $41.7 \%$ \\
\hline Every day & $19.4 \%$ \\
\hline Frequency of drug use prior to arrest & \\
\hline $2-3$ times per week/nearly every day & $25.0 \%$ \\
\hline Every day & $41.7 \%$ \\
\hline Substances used during the 12 months prior to current incarceration? & \\
\hline Alcohol & $82.1 \%$ \\
\hline Amphetamine/meth & $59.0 \%$ \\
\hline Marijuana & $48.7 \%$ \\
\hline Heroin/opiates & $30.8 \%$ \\
\hline Cocaine & $28.2 \%$ \\
\hline Prescription Drugs & $23.1 \%$ \\
\hline Designer Drugs & $12.8 \%$ \\
\hline Hallucinogens & $12.8 \%$ \\
\hline
\end{tabular}


Table 4: Childhood and adult abuse \& mental health histories $(\mathrm{n}=39)$.

\begin{tabular}{|c|c|c|c|}
\hline Description & $\%$ & Mean & SD \\
\hline \multicolumn{4}{|l|}{ Adverse Childhood Experiences } \\
\hline Verbal abuse & $79.5 \%$ & & \\
\hline Physical abuse & $56.4 \%$ & & \\
\hline Sexual abuse & $61.5 \%$ & & \\
\hline Emotional neglect & $56.4 \%$ & & \\
\hline Physical neglect & $25.6 \%$ & & \\
\hline Parents separated or divorced & $74.4 \%$ & & \\
\hline Mother treated violently & $31.6 \%$ & & \\
\hline An alcohol and/or drug abuser in the household & $76.3 \%$ & & \\
\hline Someone mentally ill or suicidal in household & $46.2 \%$ & & \\
\hline An incarcerated household member & $53.8 \%$ & & \\
\hline Total ACEs & & 5.59 & 2.55 \\
\hline \multicolumn{4}{|l|}{ Adult Experiences of Victimization } \\
\hline Minor physical abuse (pushing, slapping, restraining) & $87.2 \%$ & & \\
\hline Severe physical abuse (burning, choking, stabbing) & $89.7 \%$ & & \\
\hline Forced sex & $28.2 \%$ & & \\
\hline Intimidation & $87.2 \%$ & & \\
\hline Ever diagnosed with a mental illness & $92.1 \%$ & & \\
\hline Receiving medication for anxiety & $71.4 \%$ & & \\
\hline Currently classified as CCCMS & $97.1 \%$ & & \\
\hline
\end{tabular}

was 34.4, and the total years incarcerated was 12.6; on average women have been incarcerated about a third of their lives. They have also had experiences with the criminal justice system from a young age, with the average age of first arrest just over 16, and lifetime arrests averaging around 17; nearly half of the women previously served time in a juvenile justice facility. While incarcerated, many of these women have spent significant time in segregation, spending over two and a half years there on average prior to the current SHU term. Over half of the women in the sample meet criteria for alcohol use disorder and substance use disorder. Of substances used, alcohol (82\%) and amphetamines (59\%) were the most common, with over half of the women using in the 12 months prior to incarceration.

Prior to incarceration many women have had complex histories of trauma and household dysfunction. The women surveyed had experienced over 5 ACEs, on average, with experiences of verbal abuse (80\%), alcohol or drug abuse in the household (76\%), parental separation / divorce (74\%), sexual abuse (62\%), physical abuse (56\%), emotional neglect (56\%), and an incarcerated household member (54\%) impacting over half of the women. For most of the women, abuse in their adult lives was also common with over $85 \%$ experiencing minor physical abuse, severe physical abuse, and intimidation. Twentyeight percent of the women reported experiencing forced sex as an adult. Additionally, those who experienced forced sex as a minor were over $50 \%$ more likely to experience forced sex as an adult. Over $90 \%$ of women have been diagnosed with a mental illness at some point in their lives, $71 \%$ reported receiving medication for anxiety, and almost all (97\%) are currently classified as "CCCMS" - meaning they are in need of correctional case management supervision for mental health issues / behavior. This is not surprising given the research on the over-representation of women with mental health issues in SHUs and the level of childhood and adult trauma many of these women experienced.

\section{Results}

Table 5 summarizes the results of 39 women who participated in the $H T$ program and completed both pre- and post-survey evaluations. Participants showed statistically significant improvement on 10 (72\%) of the 14 measures analyzed. Specifically, there were statistically significant reductions in depression, anxiety, PTSD, all five aggression measures (physical aggression, verbal aggression, uncontrolled anger, hostility, and indirect aggression) and instrumental anger. Furthermore, there was a significant increase in social connectedness. Significant effect sizes were moderate to large, with the largest impact on physical aggression (Cohen's $d$ range of 0.389 to 0.819 ). There were not significant findings for expressive anger (the suppression of anger), resilience (self-regulation), perspective taking (understanding another person perspective), or empathetic concern (identifying with another person's emotion). Overall, these results along with the participant feedback (Sigler, Messina, \& Calhoun, in press) demonstrate that this program continues to have an impact on the lives of women housed in SHUs.

\section{Discussion}

The pilot study results have demonstrated the feasibility of delivering a successful brief intervention in the most punitive correctional environment - a SHU. As previously outlined, women housed in the SHU are often those with the most serious behavioral problems and multiple chronic disorders. Women who have been sentenced for a violent crime during their incarceration often receive a SHU sentence; however, it has been shown that women have also been moved to the SHU for minor infractions or self-harming behaviors, resulting in segregation from others. A large body of literature from

Table 5: Results for Healing Trauma participants at CIW-SHU $(\mathrm{n}=39)$.

\begin{tabular}{|l|c|c|c|c|c|}
\hline Description & $\begin{array}{c}\text { Pre-Program } \\
\text { Mean (SD) }\end{array}$ & $\begin{array}{c}\text { Post-Program } \\
\text { Mean (SD) }\end{array}$ & Change & Significance & $\begin{array}{c}\text { Cohen's } \\
\text { d }\end{array}$ \\
\hline Depression & $9.3(4.83)$ & $5.8(4.57)$ & $-3.5(5.74)$ & $\mathrm{p}<0.001$ & 0.616 \\
\hline Anxiety & $6.8(3.43)$ & $3.7(3.57)$ & $-3.1(4.21)$ & $\mathrm{p}<0.001$ & 0.741 \\
\hline PTSD $(\mathrm{n}=33)$ & $6.3(4.58)$ & $4.1(4.03)$ & $-2.2(4.51)$ & $\mathrm{p}=0.007$ & 0.504 \\
\hline Aggression & & & & & \\
\hline Physical Aggression & $23.3(7.57)$ & $18.7(7.35)$ & $-4.5(5.54)$ & $\mathrm{p}<0.001$ & 0.819 \\
\hline Verbal Aggression & $14.1(4.20)$ & $12.1(4.13)$ & $-2.0(4.29)$ & $\mathrm{p}=0.006$ & 0.465 \\
\hline Uncontrolled Anger & $19.1(6.01)$ & $17.1(5.91)$ & $-2.0(4.88)$ & $\mathrm{p}=0.013$ & 0.415 \\
\hline Hostility & $21.2(6.49)$ & $18.3(6.14)$ & $-2.8(6.62)$ & $\mathrm{p}=0.011$ & 0.430 \\
\hline Indirect Aggression & $15.5(4.98)$ & $13.6(4.79)$ & $-1.8(4.80)$ & $\mathrm{p}=0.02$ & 0.389 \\
\hline Anger & & & & & \\
\hline Instrumental Anger & $24.1(6.92)$ & $18.9(7.48)$ & $-5.2(8.22)$ & $\mathrm{p}<0.001$ & 0.633 \\
\hline Expressive Anger & $26(5.91)$ & $24.9(5.52)$ & $-1.0(6.63)$ & $\mathrm{p}=0.346$ & 0.155 \\
\hline Resilience & $12.8(3.54)$ & $13.5(3.46)$ & $0.7(3.79)$ & $\mathrm{p}=0.28$ & 0.175 \\
\hline Empathy & & & & & \\
\hline Perspective Taking & $18.5(7.68)$ & $18.4(7.26)$ & $-0.1(8.90)$ & $\mathrm{p}=0.928$ & 0.015 \\
\hline Empathic Concern & $16.3(6.11)$ & $17.8(7.09)$ & $1.5(8.98)$ & $\mathrm{p}=0.312$ & 0.168 \\
\hline Social Connectedness & $3.7(0.70)$ & $4.0(0.80)$ & $0.3(0.70)$ & $\mathrm{p}=0.017$ & 0.399 \\
\hline
\end{tabular}


[20] has concluded that segregation and isolation can exacerbate existing psychological problems and can potentially re-traumatize a trauma survivor. The CDCR holds the responsibility of the provision of effective rehabilitative program services for the women under their care, including those with the most complex needs who are housed in the most punitive setting.

There is great difficulty in creating a therapeutic environment within a high security and segregated environment. The commitment from CDCR helped mitigate challenges associated with the implementation of this pilot study. Considering the physical restraints required for this level of custody, the women were able to participate in this program in small groups, while being secured to study desks that were bolted to the ground. CDCR supplied cubicle walls around the small circle of desks to create a level of confidentiality. The participants were also permitted to have the program materials and other necessary supplies for program activities. Without the cooperation from CDCR, programming in the SHU would not have been possible.

This study has demonstrated the preliminary effectiveness of $H T$ for women housed in SHUs. The results showed significantly positive outcomes, with moderate to high effect sizes, for women incarcerated for violent or serious crimes on reductions in depression, anxiety, PTSD, aggression, and instrumental anger, and increases in social connectedness. It is important to reiterate that $H T$ is a 6-session brief intervention (2-hour sessions), indicating that an appropriate brief intervention can be significantly impactful for justice-involved women to reduce trauma-related difficulties and increase well-being. Traumainformed brief interventions can also be beneficial in institutional housing areas requiring short lengths of stay, such as reception centers and/or brief SHU sentences.

The study has also contributed to the understanding of the complex issues surrounding histories of trauma, abuse, violence, and justice-involved women. The results substantiate the existing literature outlining consistent factors associated with women housed in SHU facilities (e.g., a high prevalence of childhood trauma, violence, victimization, and adult mental health problems). In fact, the sample of women in this study reported extensive histories of ACEs, household dysfunction, criminal justice involvement beginning at an early age, frequent drug and alcohol use prior to incarceration, continued violence and victimization as adults, multiple SHU sentences and ongoing mental health challenges. As these are factors consistently found among women in SHU facilities, it becomes clear that insufficient attention is being paid to the detrimental issue surrounding isolation as punishment. There is potential for effective trauma-based program services to be implemented in the general prison population, thus reducing the reliance on isolation and punitive measures to create a safe custody environment (further indicated by the large reduction in aggression). The findings from this study provide a foundation of procedures and services to provide appropriate services for women housed in a SHU, with the longer-term goal of eradicating the need for a SHU facility.

\section{Limitations}

The conclusions should be interpreted with caution as there are limitations. The study used a single group pretest-posttest design and did not include a comparison group of SHU women who did not participate in HT. Therefore, it is difficult to judge whether improvements in posttest measures were indeed solely a product of participation in the curriculum. This study also relied on findings from a small sample size of incarcerated women in a California SHU. A small sample size increases the likelihood of a Type II error potentially skewing the results and decreasing the power of the study. However, even with low power, the analyses still revealed significant change over time in the hypothesized direction (71\% significant positive change among measured outcomes). A larger sample size would provide more power to detect the potential impact of measures that did reach statistical significance, but were in the hypothesized direction (i.e., instrumental anger, resilience, perspective taking, and empathetic concern). It is possible that resilience to stress and interpersonal reactivity are challenging outcomes to validly measure in a punitive environment. The SHU operates on isolation and endorses solitary reflection with little emphasis on empathy.

The focus on a small sample of women in secure confinement in California also raises concerns about generalizability to other state SHU populations or lower level offenders; however, the findings are consistent with other trauma-informed and gender-responsive program studies with women in the general population serving longterm or life sentences from multiple prisons in Michigan [39,44,45,49].

Additionally, the current study relied on self-administered survey data. We did not have access to objective measures (i.e., records-based data) to determine previous mental health diagnoses or to substantiate self-reported histories of crime and addiction. The questions on the ACE survey were also limited, as the results regarding histories of sexual and physical abuse were dichotomous (yes or no) questions, which did not inquire about the perpetrator(s) of the abuse, the age at which it occurred, or the duration of the abuse. Thus, responses to the questions reflected each respondent's interpretation of the questions, including those regarding physical and sexual assault.

\section{Strengths}

There are notable strengths to this pilot project. The program curricula itself, $H T$, is a manualized intervention providing both a detailed facilitator guide and a participant workbook. The use of a manualized curricula creates the ability to monitor fidelity and to provide reliability of program delivery. There were two HT facilitators throughout the course of the pilot project, and both had been trained by the program author, enhancing reliability of facilitation. The HT program also uses a variety of therapeutic approaches to address the impact of trauma: CBT, expressive arts, mindfulness, and guided imagery. It is also gender responsive in that it reflects an understanding of the realities of women's lives and is guided by the Relational-Cultural Theory of women's psychological development. Finally, the HT content was created to specifically address justice-involved women's needs, such as, learning styles, motivation, abilities, and strengths. 
This pilot project has also been replicated with men serving sentences in two California SHUs implementing Exploring Trauma: A Brief Intervention for Men (Covington \& Rodriguez, 2016) [50]. The findings from the men's SHU pilot project are consistent with the findings from the current study and further demonstrate the feasibility of implementing a brief trauma-informed intervention in a SHU setting [51]. The HT program continues to operate in the CIW SHU and has been expanded to the general population of women. Based on the positive results of the evaluation, the $H T$ program is also being implemented at the Central California Women's Facility in the reception center, in the Administrative Housing Unit, and for the condemned women. The CDCR further participated in the expansion of the male version of the trauma-informed brief intervention in the general population at five other male facilities in California (randomized controlled trials underway).

The pilot study findings provide a knowledge base to create larger more rigorous studies, which can ultimately identify appropriate policy and program opportunities for women in the highest levels of security. As larger and more rigorous studies are undertaken, there should be a focus on the longer-term impact of the brief intervention; whether the changes that occur over the course of participation persist or become extinct over some period of time. Future research should also focus on the potential that trauma-informed interventions can have on reducing recidivism after release from prison (Figure 1).
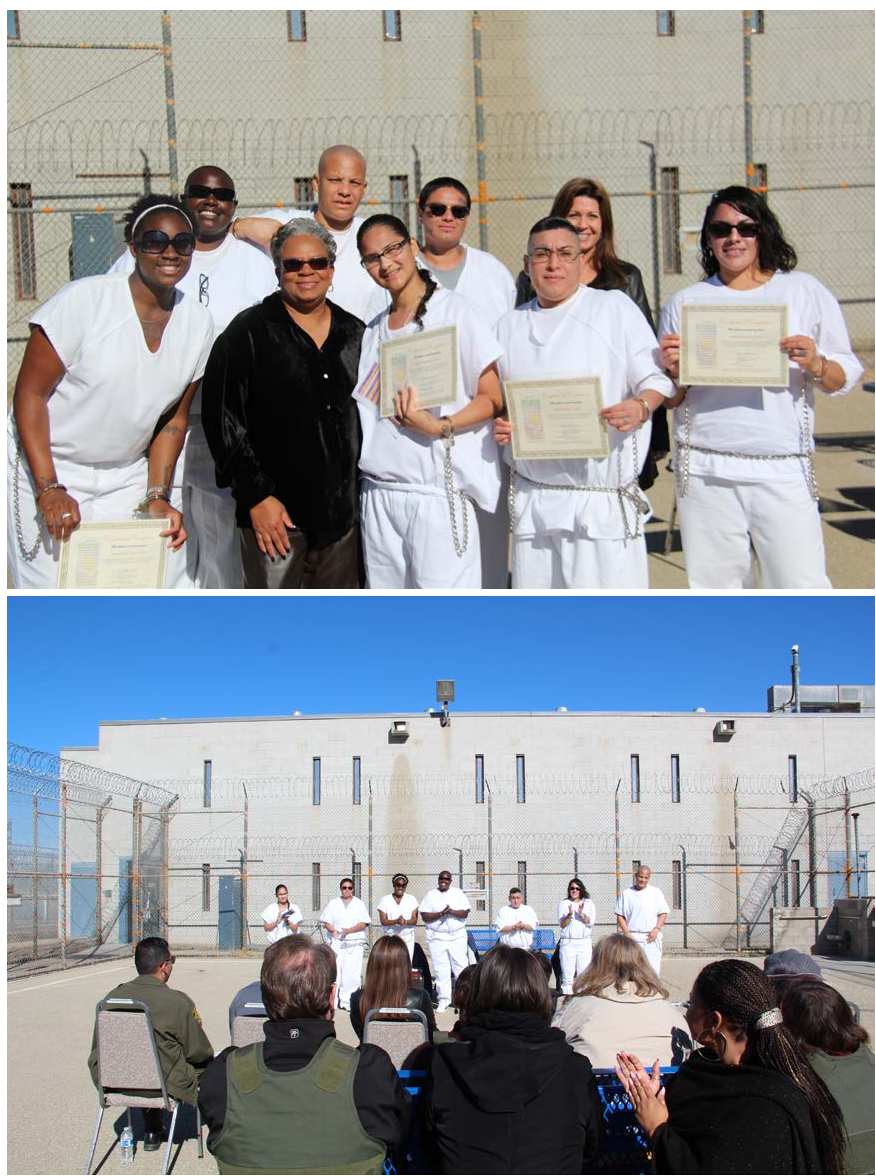

Figure 1: Graduation photos of the women in the SHU that participated in the study.

\section{Acknowledgement}

This pilot project would not have been possible without the strong support and engagement of the California Department of Corrections and Rehabilitation (CDCR) Lead Administrators such as former FOPS Directors, Jay Virbel and Amy Miller, and the institutional staff at the California Institution for Women (CIW) including former Warden Molly Hill, the current Warden Richard Montes, Lieutenant Joseph Spinney, and the former Community Resource Manager, Ronnie Shoupe. We are especially grateful to Dr. Stephanie Covington, the author of the trauma-informed program for women, Healing Trauma: A Brief Intervention for Women. Dr. Covington's dedication to enhancing the wellbeing of incarcerated women around the world is demonstrated in her collective publication and gender-responsive curriculum development. We would also like to acknowledge retired Captain Rochelle Leonard for her unwavering dedication and facilitation of the Healing Trauma program inside the facility. We would also like to thank the Supervising Psychiatric Social Worker, Karen Vertti and the research assistant, Claire Samuelson for their voluntary assistance with the delivery of program in the SHU. We are grateful for CDCR's and CIW's continued support of the program, graduations, and ongoing navigation of the program in a difficult environment. Finally, we are indebted to the women who so kindly volunteered their time, insights, ideas and reflections from participating in Healing Trauma to this project.

\section{Funding}

This pilot project was funded by the California Department of Corrections and Rehabilitation, Department of Rehabilitative Programs (DRP), via the Innovative Long-Term Offender Programming Grants - Round III, Contract \#5606920 with Envisioning Justice Solutions, Inc.

Dr. Stephanie Covington, Co-director of the Center for Gender and Justice, was provided a subcontract with Envisioning Justice Solutions, Inc. to implement the program training and curriculum.

\section{References}

1. Covington SS, Russo R (2011, rev 2016) Healing Trauma: A Brief Intervention for Women CD-Rom. Center City, MN: Hazelden.

2. Bronson J, Carson EA (2019) Prisoners in 2017. Washington, DC: U.S. Department of Justice, Office of Justice Programs, Bureau of Justice Statistics.

3. Messina N, Calhoun S (2018) Healing Trauma SHU Final Report. The California Department of Corrections and Rehabilitation.

4. Messina N, Grella C, Burdon W, Prendergast M (2007) Childhood adverse events and current traumatic distress: A comparison of men and women prisoners. Criminal Justice and Behavior 34: 1385-1401. [crossref]

5. Block CR, Blokland AAJ, Van der Werff C, Van Os R., Nieuwbeerta, P (2010) Longterm patterns of offending in women. Feminist Criminology 5: 73-107.

6. Cauffman EE (2008) Understanding the female offender. Future of Children 18: 119142. [crossref]

7. Messina N, Grella C (2006) Childhood trauma and women's health outcomes in a California prison population. American Journal of Public Health 96: 1842-1848. [crossref]

8. Messina N, Burdon W, Hagopian G, Prendergast M (2006) Predictors of prison TC treatment outcomes: A comparison of men and women participants. American Journal of Drug and Alcohol Abuse 32: 7-28. [crossref] 
9. Grella C, Stein J, Greenwell L (2005) Associations among childhood trauma, adolescent problem behaviors, and adverse adult outcomes in substance-abusing women offenders. Psychology of Addictive Behaviors 19: 43-53. [croosref]

10. Reisig MD, Holtfreter K, Morash M (2006) Assessing recidivism risk across female pathways to crime, justice quarterly 23: 384-405.

11. Owen BA (1998) "In the Mix": Struggle and Survival in a Women's Prison. United States: State University of New York Press. [11]

12. Owen B, Wells J, Pollack J (2017) "In Search of Safety": Confronting inequality in women's imprisonment. University of California Press: Oakland, California. [12]

13. Babcock JC, Miller SA, Siard C (2003) Toward a typology of abusive women: differences between partner-only and generally violent women in the use of violence. Psychology of Women Quarterly 27: 153-61.

14. Kruttschnitt C, Gartner R, Ferraro K (2002) Women's involvement in serious interpersonal violence. Aggression and Violent Behavior 7: 529-565.

15. Kubiak SP, Fedock G, Kim WJ, Bybee D (2017) Examining perpetration of physical violence by women: The influence of childhood adversity, victimization, mental illness, substance abuse, and anger. Violence and Victims 32: 22-45. [crossref]

16. Saxena P, Messina N. Under review. Perpetration of abuse and early criminal justice involvement among incarcerated women.

17. West HC, Sabol WJ, Greenman, SJ (2010) Prisoners in 2009 (NCJ 231675). Bureau of Justice Statistics Bulletin. Washington DC: Bureau of Justice Statistics.

18. Battle CL, Zlotnick C, Najavits LM, Gutierrez M, Winsor C (2003) Posttraumatic stress disorder and substance use disorder among incarcerated women.

19. Browne A, Cambier A, Agha S (2011) Prisons within prisons: The use of segregation in the United States. Federal Sentencing Reporter 24: 46-49

20. Haney C, Lynch M (1997) Regulating prisons of the future: The psychological consequences of solitary and supermax confinement. New York University. Review of Law and Social Change 23: 477-570.

21. Smith PS (2006) The effects of solitary confinement on prison inmates: A brief history and review of the literature. Crime and Justice 34: 441-528.

22. Grassian, S (2006) Psychiatric effects of solitary confinement. Washington University Journal of Law and Policy 22: 325-383.

23. Arrigo BA, Bullock JL (2008) The psychological effects of solitary confinement on prisoners in supermax units: Reviewing what we know and recommending what should change. International Journal of Offender Therapy and Comparative Criminology 52: 622-640.

24. Winters A (2018) Alone in isolation: A clinician's guide to women in solitary confinement. Criminal Behaviour and Mental Health 28: 217-222.

25. Haney C (2008) A culture of harm: Taming the dynamics of cruelty in supermax prisons. Criminal Justice and Behavior 35: 956-984.

26. American Psychological Association (2016) Statement on the Solitary Confinement of Juvenile Offenders. Washington, DC: American Psychological Association, Public Information Government Relations Office.

27. Kaba F, Lewis A, Glowa-Kollisch S, Hadler J, Lee D, et al. (2014) Solitary confinement and risk of selfharm among jail inmates. American Journal of Public Health 104: 442447. [crossref]

28. Jordan J, Kaplan A, Miller JB, Stiver I, Surrey J (1991) Women's growth in connection: Writings from the Stone Center: New York: Guilford Press.

29. Pickard H (2015) Self-Harm as Violence: When Victim and Perpetrator Are One. In: Widdows H, Marway H, editors. Women and Violence: The Agency of Victims and Perpetrators. London: Palgrave Macmillan; Chapter 4

30. Miller JB (1976) Toward a new psychology of women. Boston: Beacon Press.

31. Garcia-Coll C, Duff K (1995) Reframing the needs of women in prison: A relational and diversity perspective. Final report. Women in prison pilot project. Wellesley, MA: The Stone Center.
32. Garcia-Coll C, Surrey J, Buccio-Notaro P, Molla B (1998) Incarcerated mothers Crimes and punishments. In C. Garcia-Coll, J.L. Surrey, \& K. Weingaten (Eds.), Mothering against the odds: Diverse voices of contemporary mothers (pp. 255-274). New York: The Guilford Press.

33. Haney C (2003) Mental health issues in long-term solitary and "supermax" confinement. Crime \& Delinquency 49: 124-156.

34. Houser K, Belenko S (2015) Disciplinary responses to misconduct among female prison inmates with mental illness, substance use disorders, and co-occurring disorders. Psychiatric Rehabilitation Journal 38: 24-34. [crossref]

35. Wright E, Salisbury E, Van Voorhis P (2007) Predicting the prison misconducts of women offenders. The importance of gender-responsive needs. Journal of Contemporary Criminal Justice 23: 310-340.

36. Drapalski AL, Leith J, Dixon L (2009) Involving families in the care of persons with schizophrenia and other serious mental illnesses: history, evidence, and recommendations. Clinical Schizophrenia \& Related Psychoses 3: 39-49.

37. Teplin LA, Abram KM, McClelland GM (1996) Prevalence of psychiatric disorders among incarcerated women. Archives of General Psychiatry 53: 505-512. [crossref]

38. SAMHSA (2014) SAMHSA's Concept of Trauma and Guidance for a TraumaInformed Approach SAMHSA's Trauma and Justice Strategic Initiative.

39. Messina N, Calhoun S, Braithwaite J (2014) Trauma-informed treatment decreases posttraumatic stress disorder among women offenders. Journal of Trauma \& Dissociation 15: 6-23. [crossref]

40. Covington SS (2014) Beyond Violence: A prevention program for criminal justiceinvolved women. Hoboken, NJ: John Wiley \& Sons, Inc.

41. Fazel S, Bains P, Doll H (2006) Substance abuse and dependence in prisoners: A systematic review. Addiction 101: 181-191. [crossref]

42. Papalia N, Spivak B, Daffern M, Ogloff J (2019) A meta-analytic review of the efficacy of psychological treatments for violent offenders in correctional and forensic mental health settings. Clinical Psychology,Science and Practice 26: 2- 28.

43. Mukamal D, Abarbanel S, Quan L (2014) Reallocation of Responsibility: Changes to the Correctional System in California Post-Realignment.

44. Office of the Inspector General (2013) Special Review: Female Inmates Serving Security Housing Unit Terms in the California Department of Corrections and Rehabilitation.

45. Kubiak SP, Fedock G, Tillander E, Kim WJ, Bybee D (2014a) Testing a violenceprevention intervention for incarcerated women using a randomized control trial. Research on Social Work Practice 1-15.

46. Kubiak SP, Fedock G, Tillander E, Kim WJ, Bybee D (2014b) Assessing the feasibility and fidelity of an intervention for women with violent offenses. Evaluation and Program Planning 42: 1-10.

47. Saxena, P., Messina, M. \& Grella, C. (2014) Who Benefits from Gender Responsive Treatment?Accounting for Abuse History on Longitudinal Outcomes for Women in Prison. Crim Justice Behav 41: 417-432. [crossref]

48. Covington S (2019) Helping women recover: A program for treating addiction (3rd ed.). Hoboken, NJ: Wiley.

49. Messina N, Braithwaite J, Calhoun S, Kubiak S (2016) Examination of a violence prevention program for serious female offenders. Violence and Gender 3: 143-149.

50. Covington SS, Rodriguez R (2016) Exploring Trauma: A Brief Intervention for Men. Center City, MN: Hazelden Publishing.

51. Messina N, Burdon W (2018) Moving Beyond Violence Final Report, Corcoran State Prison and Pelican Bay SHU. The California Department of Corrections and Rehabilitation.

\section{Citation:}

